\title{
The association between tobacco and the risk of asthma, rhinoconjunctivitis and eczema in children and adolescents: analyses from Phase Three of the ISAAC programme
}

\author{
Edwin A Mitchell, ${ }^{1}$ Richard Beasley, ${ }^{2}$ Ulrich Keill, ${ }^{3}$ Stephen Montefort, ${ }^{4}$ \\ Joseph Odhiambo, ${ }^{5}$ and the ISAAC Phase Three Study Group*
}

\begin{abstract}
- Additional tables are published online only. To view these files please visit the journal online (http://dx.doi.org/ 10.1136/thoraxjnl-2011200901).

'Department of Paediatrics: Child and Youth Health, Faculty of Medical and Health Sciences, University of Auckland, Auckland, New Zealand ${ }^{2}$ Medical Research Institute of New Zealand, Wellington, New Zealand

${ }^{3}$ Institute of Epidemiology and Social Medicine, University of Muenster, Muenster, Germany ${ }^{4}$ Department of Medicine, University of Malta, Malta ${ }^{5}$ Centre Respiratory Diseases Research Unit, Kenya Medical Research Institute, Nairobi, Kenya
\end{abstract}

\section{Correspondence to}

Professor Edwin A Mitchell, Department of Paediatrics: Child and Youth Health, Faculty of Medical and Health Sciences, The University of Auckland, Private Bag 92019, Auckland, New Zealand;

e.mitchell@auckland.ac.nz

*ISAAC Phase Three Study Group are listed in appendix 1.

Received 3 August 2011 Accepted 16 May 2012

Published Online First

12 June 2012
ABSTRACT

Background Exposure to parental smoking is associated with wheeze in early childhood, but in 2006 the US Surgeon General stated that the evidence is insufficient to infer a causal relationship between exposure and asthma in childhood and adolescents.

Aims To examine the association between maternal and paternal smoking and symptoms of asthma, eczema and rhinoconjunctivitis.

Methods Parents or guardians of children aged 6-7 years completed written questionnaires about symptoms of asthma, rhinoconjunctivitis and eczema, and several risk factors, including maternal smoking in the child's first year of life, current maternal smoking (and amount) and paternal smoking. Adolescents aged 13-14 years self completed the questionnaires on these symptoms and whether their parents currently smoked. Results In the 6-7-year age group there were 220407 children from 75 centres in 32 countries. In the 13-14year age group there were 350654 adolescents from 118 centres in 53 countries. Maternal and paternal smoking was associated with an increased risk of symptoms of asthma, eczema and rhinoconjunctivitis in both age groups, although the magnitude of the $\mathrm{OR}$ is higher for symptoms of asthma than the other outcomes. Maternal smoking is associated with higher ORs than paternal smoking. For asthma symptoms there is a clear dose relationship (1-9 cigarettes/day, OR 1.27; 10-19 cigarettes/day, OR 1.35; and $20+$ cigarettes/day, OR 1.56). When maternal smoking in the child's first year of life and current maternal smoking are considered, the main effect is due to maternal smoking in the child's first year of life. There was no interaction between maternal and paternal smoking.

Conclusions This study has confirmed the importance of maternal smoking, and the separate and additional effect of paternal smoking. The presence of a dose-response effect relationship with asthma symptoms suggests that the relationship is causal, however for eczema and rhinoconjunctivitis causality is less certain.

The effect of environmental tobacco smoke exposure (ETS) on respiratory health has been of interest for many years. In 2006 the US Surgeon General concluded that 'the evidence is sufficient to infer a causal relationship between secondhand smoke exposure from parental smoking and the

\section{Key messages}

What is the key question?

- What is the association between maternal and paternal smoking and symptoms of asthma eczema and rhinoconjunctivitis?

What is the bottom line?

- This study has confirmed the association of maternal smoking, and identified a separate and additive association between paternal smoking and the risk of symptoms of asthma, eczema and rhinoconjunctivitis.

\section{Why read on?}

- The results of this large study (over 570000 children and adolescents in 53 countries) were consistent throughout the world and were independent of the income of the country.

onset of wheeze illnesses in early childhood' and 'that the evidence is suggestive but not sufficient to infer a causal relationship between secondhand smoke exposure from parental smoking and the onset of childhood asthma'. ${ }^{1}$ While a recent systematic review and meta-analysis has quantified the strength of the associations, ${ }^{2}$ the data come predominantly from developed countries. The importance of the age of exposure to ETS is not well established, nor is the relative importance of maternal and paternal smoking.

In contrast with the number of studies examining the association of ETS with asthma, there are fewer studies examining the association between ETS and either eczema or rhinoconjunctivitis, and these have provided conflicting results.

The aims of this study were to examine the association between maternal and paternal smoking and symptoms of asthma, rhinoconjunctivitis and eczema, to assess the relative importance of maternal and paternal smoking, to look for consistency in these findings from many different countries, including developing countries, and to determine if there is a dose-response effect, which if present would support a causal relationship. 


\section{METHODS}

International Study of Asthma and Allergies in Childhood (ISAAC) Phase Three is a multicentre, multicountry, crosssectional study of children (aged 6-7 years) and adolescents (aged 13-14 years) chosen from a random sample of schools in a defined geographical area. The parent or guardian completed the questionnaire for the children and for the adolescents the questionnaire was self-completed. The methods have been described in detail previously. ${ }^{3}$

\section{Outcomes}

Current wheeze was identified by a positive response to the question: 'Has your child/have you had wheezing or whistling in the chest in the past 12 months?'

Severe asthma symptoms were identified by fulfilling one or more of the following criteria:

1. Four or more attacks of wheezing in the past 12 months.

2. Sleep disturbance due to wheezing occurring one or more nights per week in the past 12 months.

3. Wheezing limiting speech to one or two words at a time between breaths in the past 12 months.

Asthma (the diagnosis) was defined as a positive response to the question: 'Has your child/have you ever had asthma?'

Current rhinoconjunctivitis was identified by a positive response to each of the following questions:

1. In the past 12 months has your child/have you had a problem with sneezing, or a runny or blocked nose when he/she did not have a cold or the flu?

2. If yes, has this nose problem been accompanied by itchy watery eyes?

Current eczema was identified by a positive answer to each of the following questions:

1. Has your child/have you ever had an itchy skin rash, which was coming and going for at least 6 months?
2. If yes, has your child/have you had this itchy rash at any time in the past 12 months?

3. If yes, has this itchy rash at any time affected any of the following places - the folds of the elbows, behind the knees, in front of the ankles, under the buttocks, or around the neck, ears, or eyes?

The prevalence of wheeze and asthma is higher in children with rhinoconjuctivitis and eczema, ${ }^{4}$ and this might account for the association between parental smoking and eczema and rhinoconjunctivitis; therefore, the risk of symptoms of eczema and rhinoconjunctivitis in the absence of current asthma symptoms was also examined.

In addition, a video questionnaire of asthma symptoms was administered to the adolescents. The video question used was the sequence on current wheeze at rest defined as a positive response to the question: 'Has your breathing been like this in the past year?' The video asthma questionnaire was validated against the written questionnaire. ${ }^{5}$

\section{Explanatory variables}

The following questions were used to assess smoking by the parents of the subjects. For children aged 6-7 years:

1. Does your child's mother (or female guardian) smoke cigarettes?

If yes, about how many cigarettes does the child's mother (or female guardian) smoke each day?

2. Does your child's father (or male guardian) smoke cigarettes?

If yes, about how many cigarettes does the child's father (or male guardian) smoke each day?

3. Did your child's mother (or female guardian) smoke cigarettes during your child's first year of life?

For adolescents aged $13-14$ years:

1. Does your mother (or female guardian) smoke cigarettes?

2. Does your father (or male guardian) smoke cigarettes?

Table 1 Association between tobacco smoking by the parents and symptoms of asthma, eczema and rhinoconjunctivitis at $6-7$ and $13-14$ years of age

\begin{tabular}{|c|c|c|c|}
\hline \multirow[b]{2}{*}{ Symptom } & \multirow[b]{2}{*}{ Tobacco question } & \multicolumn{2}{|l|}{ Age group } \\
\hline & & $6-7$ years & $13-14$ years \\
\hline \multirow[t]{3}{*}{ Current wheeze } & Current paternal smoking & $1.17(1.12$ to 1.21$)$ & $1.20(1.15$ to 1.24$)$ \\
\hline & Current maternal smoking & $1.28(1.22$ to 1.34$)$ & 1.32 (1.26 to 1.37$)$ \\
\hline & Mother smoked first year of life & $1.36(1.29$ to 1.43$)$ & * \\
\hline \multirow[t]{2}{*}{ Current wheeze (video) } & Current paternal smoking & * & $1.22(1.15$ to 1.29$)$ \\
\hline & Current maternal smoking & * & 1.41 (1.32 to 1.49$)$ \\
\hline \multirow[t]{3}{*}{ Severe asthma symptoms } & Current paternal smoking & $1.23(1.16$ to 1.30$)$ & $1.26(1.20$ to 1.32$)$ \\
\hline & Current maternal smoking & $1.32(1.24$ to 1.41$)$ & $1.38(1.31$ to 1.45$)$ \\
\hline & Mother smoked first year of life & $1.44(1.33$ to 1.55$)$ & * \\
\hline \multirow[t]{3}{*}{ Asthma ever } & Current paternal smoking & $1.11(1.06$ to 1.15$)$ & $1.08(1.04$ to 1.12$)$ \\
\hline & Current maternal smoking & $1.26(1.20$ to 1.32$)$ & $1.20(1.16$ to 1.25$)$ \\
\hline & Mother smoked first year of life & 1.34 (1.27 to 1.42$)$ & $*$ \\
\hline \multirow[t]{3}{*}{ Current eczema symptoms } & Current paternal smoking & 1.09 (1.04 to 1.13$)$ & $1.19(1.14$ to 1.25$)$ \\
\hline & Current maternal smoking & $1.15(1.09$ to 1.21$)$ & 1.22 (1.16 to 1.28$)$ \\
\hline & Mother smoked first year of life & $1.20(1.13$ to 1.27$)$ & $*$ \\
\hline \multirow[t]{3}{*}{ Current rhinoconjunctivitis } & Current paternal smoking & $1.08(1.04$ to 1.13$)$ & 1.15 (1.11 to 1.19$)$ \\
\hline & Current maternal smoking & $1.12(1.06$ to 1.18$)$ & $1.20(1.15$ to 1.25$)$ \\
\hline & Mother smoked first year of life & $1.17(1.10$ to 1.24$)$ & * \\
\hline \multirow[t]{3}{*}{ Eczema without wheeze } & Current paternal smoking & $1.06(1.01$ to 1.11$)$ & $1.15(1.09$ to 1.20$)$ \\
\hline & Current maternal smoking & $1.10(1.03$ to 1.17$)$ & $1.12(1.05$ to 1.18$)$ \\
\hline & Mother smoked first year of life & $1.11(1.04$ to 1.19$)$ & $*$ \\
\hline \multirow[t]{3}{*}{ Rhinoconjunctivitis without wheeze } & Current paternal smoking & 1.04 (0.99 to 1.09$)$ & $1.11(1.07$ to 1.16$)$ \\
\hline & Current maternal smoking & $1.05(0.98$ to 1.12$)$ & $1.11(1.06$ to 1.16$)$ \\
\hline & Mother smoked first year of life & $1.05(0.98$ to 1.13$)$ & $*$ \\
\hline
\end{tabular}

Data are $\mathrm{OR}(95 \% \mathrm{Cl})$ and are adjusted for gender, language, region and Gross National Income (GNI) category.

*Data not collected. 
To assess the presence of a dose-response relationship, the number of cigarettes smoked were categorised as 0, 1-9, 10-19 and $20+$ per day. In addition, combinations of maternal and paternal smoking were examined for both age groups, and combinations of maternal smoking in the child's first year of life and current maternal smoking were examined in the 6-7-year age group.

\section{Study sample}

For the 6-7-year age group, data were submitted to the ISAAC International Data Centre (IIDC) from 165 centres in 65 coun- tries with 421543 participants. There were 21 centres in 16 countries (32732 children) excluded as the response rate was $<60 \%$ or there were $<1000$ participants. There were a further 69 centres in 38 countries (168404 children) that did not include the risk factor questionnaire. The final risk factor dataset for the younger age group comprised 75 centres from 32 countries with 220407 children.

For the adolescent group, data from 242 centres in 98 countries with 814837 participants were submitted to the IIDC. There were nine centres from six countries (16152 adolescents) excluded as the response rate was $<70 \%$ or there were $<1000$ participants.

Country (\% maternal smoking) Spain (40\%) Chile (36\%)

Hungary $(33 \%)$

Poland (32\%) New Zealand (27\%) Malta (25\%)

Venezuela(24\%)

Estonia (24\%)

Portugal (24\%)

Canada (24\%)

Uruguay (24\%)

Isle ofman (22\%)

Syrian Arab Republic (21\%)

Japan (19\%)

Belgium (19\%)

Lithuania(13\%)

Mexico (11\%)

Colombia (8\%)

Brazil (8\%)

South Korea $(6 \%)$

Taivan (5\%)

Kyrgyzstan (4\%)

Panama (4\%)

Indonesia(4\%)

Barbados (3\%)

Iran (3\%)

Singapore (3\%)

Malaysia (2\%)

Thailand (2\%)

Nigeria(1\%)

India (1\%)

Sultanate of Oman (1\%)
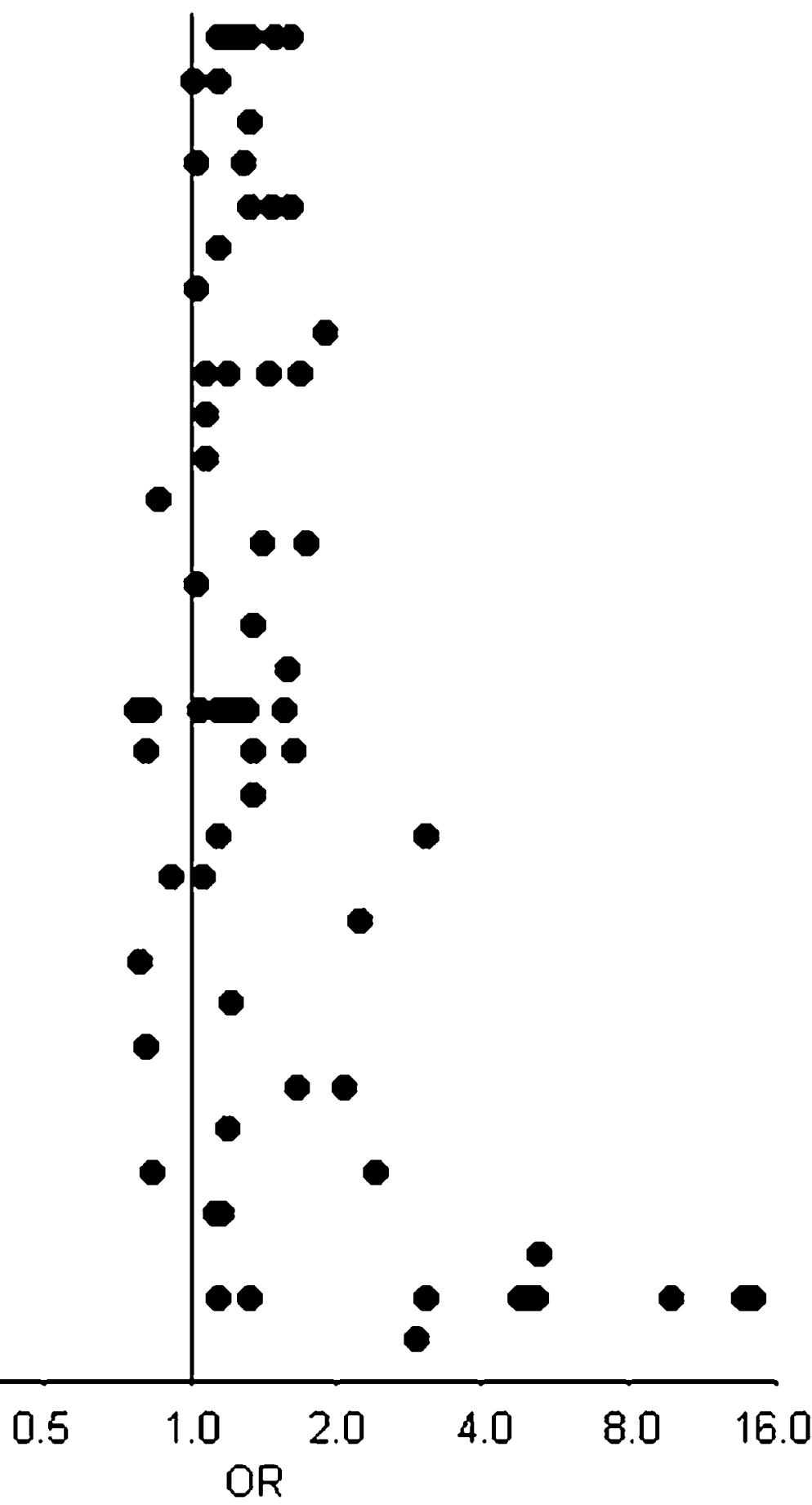

Figure 1 ORs for the association between current maternal smoking and current wheeze by country in children aged 6-7 years. For every country, the percentage of children exposed to maternal smoking is stated in brackets. 
There were a further 111 centres from 59 countries (437086 adolescents) that did not include the risk factor questionnaire. Four centres did not collect data on current maternal and paternal smoking. The final risk factor dataset for the older age group comprised 118 centres from 53 countries with 350654 adolescents.

In addition, some centres did not collect data on specific risk factor questions or the response rate to the specific question was

Country (\% maternal smoking)

Former YugoslavRepublicofMacedonia (F YROM)(51\%) Spain (41\%)

Poland (39\%)

Uruguay (37\%)

Hungary ( $36 \%)$

Argentina (33\%)

Isle ofman (33\%)

Chile (29\%)

USA $(28 \%)$

Venezuela $(28 \%)$

South Africa (28\%)

New Zealand $(27 \%)$

Channel Islands $(27 \%)$

Syrian Arab Republic (26\%)

Estonia (26\%)

United Kingdom (25\%)

Malta $(24 \%)$

Samoa(24\%)

Bolivia (23\%)

Japan $(23 \%)$

Finland (22\%)

Peru (21\%)

Portugal (21\%)

Lithuania (19\%)

Fiji (19\%)

Mexico (18\%)

Brazil (18\%)

Colombia (16\%)

Philippines (14\%)

Ecuador (14\%)

South Korea (11\%)

Tainen (10\%)

Canada (9\%)

Kyrgyzstan (8\%) Gabon (6\%)

China (5\%)

Indonesia(5\%)

Cameroon (4\%)

Panama (4\%)

Malaysia (4\%)

Hong Kong ( $4 \%$ )

Singapore (3\%)

India (3\%)

Iran (3\%)

Barbados (3\%)

Sudan (2\%)

Cote d'Ivoire (2\%)

Nigeria (2\%)

Kunait $(1 \%)$

Ethiopia(1\%)

Morocos (1\%)

Sultanate of Tman (1\%)

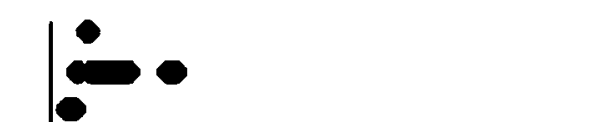

Figure 2 ORs for the association between current maternal smoking and current wheeze by country in adolescents aged 13-14 years (Tokelau excluded). For every country, the percentage of children exposed to maternal smoking is stated in brackets. 
$<70 \%$. For the 6-7-year age group the following number of centres were excluded: current maternal smoking $=1$, current paternal smoking $=2$, mother smoked in child's first year of life $=3$, amount smoked by mother $=5$, and amount smoked by father $=6$; and for the 13-14-year age group: current maternal smoking $=1$ and current paternal smoking $=10$.

\section{Statistical analysis}

To be included in the analysis, centres had to assess at least 1000 subjects (except Tokelau which was a complete country study) and to have a response rate of $>60 \%$ for the children and $>70 \%$ for the adolescents. Centres with minor deviations from protocol were included in the analyses and identified by the use of a footnote in the ISAAC publications. ${ }^{6-8}$ Odds ratios (ORs) were calculated with generalised linear mixed models, with a binomial distribution and logit link, and with centres being modelled as a random effect. Analyses were adjusted for gender, region of the world, language and gross national income. The regression models allowed for the sampling by schools by scaling the size of the sample by the design effect.

No imputation was done for missing data, as previous analyses had shown that little or no bias was introduced by limiting the multivariate analyses to children with complete data. ${ }^{9}$

To assess whether being in two smoke exposure groups, relative to being in one or the other, resulted in disproportionately high risk, the relative excess risk due to interaction and its 95\% CIs were calculated. ${ }^{10}$

The population-attributable risk of current asthma symptoms for maternal smoking was calculated with the Mantel-Haenszel approach, with the adjusted relative risk (RR) and the proportion of subjects who were exposed. ${ }^{11}$

\section{RESULTS}

Exposure values (6-7-year age group: current maternal smoking, current paternal smoking and mother smoking in first year of the child's life; 13-14-year age group: current maternal smoking and current paternal smoking) and prevalence values (current symptoms of asthma, rhinoconjunctivitis and eczema) by centre are shown in online tables 1 (6-7 years old) and 2 (13-14 years old).

Table 1 shows the association between smoking by the parents and symptoms of asthma, rhinoconjunctivitis and eczema at 6-7 and 13-14 years of age. Smoking is associated with an increased risk of symptoms of asthma, eczema and rhinoconjunctivitis. Figures 1 and 2 show the adjusted ORs for the association between current maternal smoking and asthma symptoms for each age group by country and table 2 shows these associations by region. The ORs are higher for asthma outcomes than for symptoms of rhinoconjunctivitis and eczema. The magnitude of the ORs associated with symptoms of eczema and rhinoconjunctivitis are similar, but weaker than that seen with asthma outcomes. The ORs for the 6-7-year age group are very similar to those for the 13-14-year age group. In all analyses but one current maternal smoking is associated with higher ORs than current paternal smoking; the exception is symptoms of eczema without wheeze in the 13-14-year age group. In all the 6-7-year age group analyses maternal smoking in the child's first year of life is associated with higher ORs than current maternal smoking. Furthermore, in both age groups severe symptoms of asthma are associated with higher ORs than current wheeze or asthma.

The association between all the smoking variables and symptoms of eczema without current asthma symptoms in both age groups are significant. The association between the smoking variables and symptoms of rhinoconjunctivitis without current asthma symptoms is significant for the 13-14-year age group, but not for the younger age group, although the point estimates are elevated.

For asthma in the 6-7-year age group (current wheeze, severe symptoms and asthma) there is clear evidence of a dose-response effect for current smoking by the mother and father (table 3). For example, the more cigarettes the mother currently smokes, the higher the risk of severe asthma symptoms (1-9 cigarettes/day, OR 1.27; 10-19 cigarettes/day, OR $1.35 ; 20+$ cigarettes/day, OR 1.56). A dose-response effect is not seen with symptoms of eczema and rhinoconjunctivitis.

The risk of all outcome variables is greater when the mother only smokes than when the father only smokes (except for symptoms of rhinoconjunctivitis without wheeze in the 13-14year age group) (table 4). When both the mother and father smoke the risk is increased by the expected amount; that is, the increased risk is almost exactly the same as that obtained by multiplying the OR when the mother only smokes with that when the father only smokes. There is no evidence of an interaction between these variables.

Table 5 examines the association between the combinations of smoking in the child's first year of life and current maternal smoking and symptoms of asthma, rhinoconjunctivitis and eczema. Maternal smoking in the first year of the child's life only is associated with greater risk of all symptoms than current maternal smoking only, although there is also an effect of only maternal smoking currently. Unexpectedly maternal smoking in the first year of life and currently is not associated with a further increase in risk compared with that seen with smoking in the first year of the child's life. There is a significant negative relative

Table 2 The association between current maternal smoking and current asthma symptoms by region in children aged $6-7$ and $13-14$ years

\begin{tabular}{|c|c|c|c|c|}
\hline \multirow[b]{2}{*}{ Region } & \multicolumn{2}{|c|}{ Age group 6-7 years } & \multicolumn{2}{|c|}{ Age group $13-14$ years } \\
\hline & Centres (n) & OR $(95 \% \mathrm{Cl})$ & Centres (n) & OR $(95 \% \mathrm{Cl})$ \\
\hline Africa & 1 & $5.31(0.79$ to 35.79$)$ & 10 & $1.37(1.01$ to 1.86$)$ \\
\hline Asia-Pacific & 11 & $1.18(1.00$ to 1.40$)$ & 18 & 1.39 (1.19 to 1.63$)$ \\
\hline Eastern Mediterranean & 6 & $1.48(1.20$ to 1.83$)$ & 8 & $1.28(1.05$ to 1.55$)$ \\
\hline Indian subcontinent & 14 & 4.07 (2.39 to 6.95$)$ & 16 & $2.22(1.56$ to 3.16$)$ \\
\hline Latin America & 17 & $1.13(1.02$ to 1.25$)$ & 27 & 1.32 (1.22 to 1.42$)$ \\
\hline North America & 2 & $1.00(0.75$ to 1.34$)$ & 3 & 1.79 (1.35 to 2.37$)$ \\
\hline Northern and Eastern Europe & 6 & $1.45(1.26$ to 1.67$)$ & 10 & $1.29(1.14$ to 1.45$)$ \\
\hline Oceania & 4 & $1.44(1.29$ to 1.62$)$ & 8 & 1.21 (1.07 to 1.38$)$ \\
\hline Western Europe & 13 & 1.27 (1.17 to 1.38$)$ & 17 & $1.30(1.20$ to 1.40$)$ \\
\hline
\end{tabular}

Data are $\mathrm{OR}(95 \% \mathrm{CI})$ and are adjusted for gender, language and $\mathrm{GNI}$ category. Cuernavaca did not collect data on current maternal smoking in both age groups. 
Table 3 Association between amount currently smoked by the parents and symptoms of asthma, eczema and rhinoconjunctivitis at 6-7 years of age

\begin{tabular}{|c|c|c|c|c|c|c|}
\hline \multirow[b]{2}{*}{ Symptom } & \multicolumn{3}{|c|}{ Current paternal smoking } & \multicolumn{3}{|c|}{ Current maternal smoking } \\
\hline & 1-9 cigarettes & $10-19$ cigarettes & $20+$ cigarettes & $1-9$ cigarettes & $10-19$ cigarettes & $20+$ cigarettes \\
\hline Current wheeze & $1.06(1.00$ to 1.12$)$ & 1.15 (1.08 to 1.22$)$ & $1.27(1.19$ to 1.35$)$ & 1.25 (1.17 to 1.34$)$ & $1.29(1.20$ to 1.38$)$ & 1.44 (1.31 to 1.59$)$ \\
\hline Severe asthma symptoms & $1.05(0.96$ to 1.15$)$ & $1.22(1.12$ to 1.34$)$ & $1.42(1.30$ to 1.56$)$ & $1.27(1.15$ to 1.40$)$ & $1.35(1.22$ to 1.50$)$ & $1.56(1.36$ to 1.80$)$ \\
\hline Asthma ever & $1.03(0.97$ to 1.10$)$ & $1.11(1.04$ to 1.18$)$ & 1.18 (1.11 to 1.26$)$ & 1.18 (1.09 to 1.27$)$ & $1.29(1.20$ to 1.40$)$ & $1.37(1.24$ to 1.52$)$ \\
\hline Current eczema symptoms & $1.08(1.02$ to 1.15$)$ & $1.04(0.97$ to 1.11$)$ & $1.11(1.04$ to 1.20$)$ & 1.17 (1.08 to 1.26$)$ & $1.13(1.04$ to 1.23$)$ & $1.15(1.02$ to 1.30$)$ \\
\hline Current rhinoconjunctivitis symptoms & $1.04(0.98$ to 1.11$)$ & $1.06(0.99$ to 1.13$)$ & $1.10(1.03$ to 1.18$)$ & 1.18 (1.09 to 1.27$)$ & $1.02(0.94$ to 1.11$)$ & 1.14 (1.02 to 1.28$)$ \\
\hline Eczema symptoms without wheeze & $1.08(1.01$ to 1.16$)$ & 1.01 (0.94 to 1.09$)$ & $1.02(0.94$ to 1.11$)$ & 1.07 (0.98 to 1.17$)$ & $1.11(1.00$ to 1.22$)$ & $1.08(0.94$ to 1.25$)$ \\
\hline $\begin{array}{l}\text { Rhinoconjunctivitis symptoms } \\
\text { without wheeze }\end{array}$ & $1.04(0.97$ to 1.12$)$ & $0.98(0.91$ to 1.07$)$ & $1.00(0.92$ to 1.09$)$ & $1.07(0.98$ to 1.17$)$ & $0.92(0.82$ to 1.03$)$ & $1.05(0.90$ to 1.21$)$ \\
\hline
\end{tabular}

Data are $\mathrm{OR}(95 \% \mathrm{Cl})$ and are adjusted for gender, language, region and GNI category. Reference group is 0 cigarettes per day.

excess risk due to interaction, which indicates that the risk of symptoms from the combined exposure is less than one would have expected.

Population attributable risk (PAR) for the various exposures is given in online table 3 . The PAR for current maternal smoking and the various asthma outcomes in both age groups range from $5.6 \%$ to $7.1 \%$. Figure 3 shows the PAR for maternal and paternal smoking. For example, if the prevalence of maternal smoking is $20 \%$ and paternal smoking is $25 \%$, the PAR is $8 \%$.

\section{DISCUSSION \\ Main findings}

This study has shown that parental smoking is associated with an increased risk of diagnosis and symptoms of asthma, eczema and rhinoconjunctivitis in childhood. The magnitude of the association is greater for current smoking by mothers than fathers, which may be due to children and adolescents spending more time in the presence of their mothers than their fathers. However, smoking by the mother and the father are both important.

When we examined 'severe asthma symptoms', which is clinically more meaningful, the magnitude of the ORs was even greater than that seen with current wheeze. This result reinforces the role of ETS in the severity of asthma symptoms. Furthermore, this suggests that ETS is related to asthma rather than just trivial wheeze or other respiratory symptoms. The magnitudes of the relative risks observed in this study are modest, although consistent with other meta-analyses examining these relationships. However, given how prevalent smoking is in some countries, ETS exposure is an important contributor to the burden of asthma and allergies in those countries. If maternal smoking is causally related to asthma then it might account for $5-7 \%$ of asthma cases in the world.

Maternal smoking in the child's first year of life was associated with a greater risk of symptoms for all outcome categories than current maternal smoking. Furthermore the magnitude of the risk associated with exposure to both smoking in the first year of life and current smoking was not greater than those who were only exposed to smoking in the first year of life. This indicates that early exposure to ETS is especially important. However, it needs to be recognised that we did not collect exposure data on smoking in pregnancy. As smoking in pregnancy and the first year of the child's life are highly correlated, it is possible that maternal smoking in the child's first year of life is a marker for smoking in pregnancy and that this is the more important factor. This study is not able to elucidate this.

We showed clear evidence of a dose-response effect for current maternal and paternal smoking on all the asthma outcomes; that is, the more the mother or father smoked, the greater the likelihood that the child or adolescent would develop

Table 4 Association between combinations of smoking by the parents and symptoms of asthma, eczema and rhinoconjunctivitis at $6-7$ and 13-14 years of age

\begin{tabular}{|c|c|c|c|c|}
\hline Symptom & Mother only smokes & Father only smokes & Mother and father smoke & RERI \\
\hline \multicolumn{5}{|l|}{$6-7$ years } \\
\hline Current wheeze & $1.31(1.22$ to 1.41$)$ & $1.13(1.08$ to 1.18$)$ & $1.37(1.29$ to 1.45$)$ & $-0.071(-0.182$ to 0.040$)$ \\
\hline Severe asthma symptoms & 1.31 (1.18 to 1.46$)$ & 1.19 (1.11 to 1.27$)$ & 1.46 (1.34 to 1.59$)$ & $-0.042(-0.205$ to 0.121$)$ \\
\hline Asthma ever & $1.28(1.19$ to 1.38$)$ & 1.07 (1.02 to 1.12$)$ & $1.29(1.22$ to 1.38$)$ & $-0.057(-0.168$ to 0.054$)$ \\
\hline Current eczema symptoms & $1.15(1.06$ to 1.24$)$ & 1.07 (1.02 to 1.12$)$ & $1.19(1.11$ to 1.27$)$ & $-0.029(-0.136$ to 0.078$)$ \\
\hline Current rhinoconjunctivitis symptoms & $1.13(1.04$ to 1.23$)$ & $1.07(1.02$ to 1.12$)$ & $1.16(1.09$ to 1.24$)$ & $-0.035(-0.141$ to 0.070$)$ \\
\hline Eczema symptoms without wheeze & $1.06(0.97$ to 1.16$)$ & $1.03(0.98$ to 1.09$)$ & $1.13(1.05$ to 1.22$)$ & $0.040(-0.075$ to 0.155$)$ \\
\hline Rhinoconjunctivitis symptoms without wheeze & $1.08(0.98$ to 1.19$)$ & 1.04 (0.98 to 1.09$)$ & $1.06(0.98$ to 1.15$)$ & $-0.052(-0.173$ to 0.069$)$ \\
\hline \multicolumn{5}{|l|}{$13-14$ years } \\
\hline Current wheeze & $1.27(1.19$ to 1.36$)$ & $1.13(1.07$ to 1.18$)$ & $1.43(1.36$ to 1.51$)$ & $0.040(-0.066$ to 0.146$)$ \\
\hline Current wheeze (video) & $1.38(1.25$ to 1.52$)$ & $1.17(1.10$ to 1.25$)$ & $1.50(1.39$ to 1.63$)$ & $-0.046(-0.203$ to 0.111$)$ \\
\hline Severe asthma symptoms & 1.28 (1.18 to 1.39$)$ & $1.16(1.09$ to 1.23$)$ & $1.57(1.47$ to 1.67$)$ & $0.128(-0.004$ to 0.260$)$ \\
\hline Asthma ever & $1.16(1.09$ to 1.23$)$ & 1.04 (0.99 to 1.08$)$ & $1.21(1.16$ to 1.28$)$ & $0.021(-0.064$ to 0.107$)$ \\
\hline Current eczema symptoms & $1.20(1.10$ to 1.30$)$ & $1.17(1.10$ to 1.23$)$ & $1.33(1.24$ to 1.42$)$ & $-0.040(-0.160$ to 0.080$)$ \\
\hline Current rhinoconjunctivitis symptoms & $1.15(1.08$ to 1.23$)$ & $1.12(1.07$ to 1.17$)$ & 1.27 (1.21 to 1.34$)$ & $0.000(-0.092$ to 0.093$)$ \\
\hline Eczema symptoms without wheeze & $1.16(1.06$ to 1.27$)$ & $1.16(1.10$ to 1.23$)$ & $1.18(1.10$ to 1.27$)$ & $-0.139(-0.266$ to -0.012$)$ \\
\hline Rhinoconjunctivitis symptoms without wheeze & $1.06(0.99$ to 1.13$)$ & $1.10(1.05$ to 1.15$)$ & $1.18(1.11$ to 1.25$)$ & $0.022(-0.068$ to 0.113$)$ \\
\hline
\end{tabular}


Table 5 Association between combinations of maternal smoking in the child's first year of life and current smoking and symptoms of asthma, eczema and rhinoconjunctivitis at $6-7$ years of age

\begin{tabular}{|c|c|c|c|c|}
\hline Symptom & First year of life only & Current only & Both times & RERI \\
\hline Current wheeze & $1.38(1.24$ to 1.53$)$ & $1.23(1.14$ to 1.32$)$ & 1.39 (1.31 to 1.47$)$ & $-0.218(-0.432$ to -0.004$)$ \\
\hline Severe asthma symptoms & $1.36(1.17$ to 1.58$)$ & 1.21 (1.09 to 1.34$)$ & $1.48(1.36$ to 1.61$)$ & $-0.093(-0.405$ to 0.219$)$ \\
\hline Asthma ever & $1.41(1.27$ to 1.56$)$ & $1.20(1.11$ to 1.30$)$ & $1.37(1.28$ to 1.45$)$ & $-0.247(-0.462$ to -0.031$)$ \\
\hline Current eczema symptoms & $1.19(1.06$ to 1.33$)$ & $1.11(1.03$ to 1.20$)$ & 1.21 (1.13 to 1.29$)$ & $-0.089(-0.293$ to 0.114$)$ \\
\hline Current rhinoconjunctivitis symptoms & $1.18(1.05$ to 1.33$)$ & $1.07(0.99$ to 1.16$)$ & $1.16(1.09$ to 1.24$)$ & $-0.097(-0.299$ to 0.106$)$ \\
\hline Eczema symptoms without wheeze & $1.13(0.99$ to 1.29$)$ & $1.10(1.01$ to 1.20$)$ & $1.11(1.02$ to 1.20$)$ & $-0.086(-0.317$ to 0.145$)$ \\
\hline Rhinoconjunctivitis symptoms without wheeze & $1.08(0.93$ to 1.25$)$ & $1.03(0.94$ to 1.13$)$ & $1.03(0.94$ to 1.12$)$ & $-0.123(-0.343$ to 0.096$)$ \\
\hline
\end{tabular}

Data are OR $(95 \% \mathrm{Cl})$ and are adjusted for gender, language, region and GNI category. Reference group: mother non-smoker for first year of child's life and non-smoker now.

RERI, relative excess risk due to interaction between the two smoking exposures.

asthma symptoms. The presence of a dose-response effect is strong evidence for a causal relationship.

We found a weak but consistent association between ETS and symptoms of eczema. A dose-response effect relationship was not seen between amount smoked and symptoms of eczema. In contrast to asthma, there have been fewer studies of the association between smoking and eczema. Smoking has been shown to increase the risk in adults in Sweden, ${ }^{12}$ but not in Norway. ${ }^{13}$ In children aged 3 years, in utero and postnatal exposure were not associated with eczema ${ }^{14}$ nor was an effect seen in children aged $0-12$ years. ${ }^{15}$ However, in a study of children aged 6 years an increased risk of eczema was associated with urinary cotinine levels. ${ }^{16}$

Finally we found that the association between ETS and symptoms of rhinoconjuctivitis was even weaker and for many of the analyses did not reach statistical significance. Furthermore, a dose-response relationship was not seen between the amount smoked and symptoms of rhinoconjunctivitis. Studies examining the association between smoking and rhinoconjunctivitis are also conflicting. One study reported a reduced risk of rhinoconjunctivitis for adult smokers and their children. ${ }^{17}$ Another showed a decreased risk of hayfever in adolescents who were exposed to tobacco in utero. ${ }^{18}$ However, in the ISAAC Phase Two Study there was an increased risk of rhinoconjunctivitis in children aged 9-11 years who had been exposed to maternal smoking during pregnancy. ${ }^{19}$

\section{Strengths and limitations}

The strengths of this multicentre study were its power, size and multinational nature. The younger age group comprised 75 centres from 32 countries with 220407 children and the adolescent group comprised 118 centres from 53 countries with

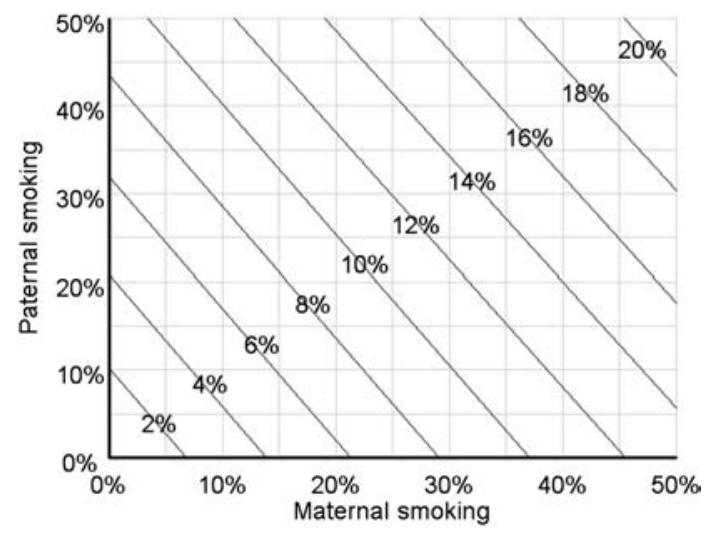

Figure 3 The population attributable risk for current wheeze for the combinations of the prevalence of maternal and paternal smoking assuming they are independent.
350654 adolescents. As a result, we established the consistency of the association of ETS with the presence of asthma and other allergic disorders in various populations with different prevalences of asthma and allergies, different exposure levels and different cultures and economic development. Many previous studies have been conducted in developed countries and the meta-analyses reflect this. ${ }^{2}$ This study extends the metaanalyses by including many countries that are less developed and markedly increased the size and number of the studies examining these relationships. We mainly used self-reported symptoms rather than doctors' diagnoses to avoid major diagnostic differences related to access to medical care, language and medical practice. Publication bias has been avoided in this study as the data from each centre in the study were included.

Limitations of this study also need to be considered. The outcomes and exposures were assessed by questionnaire, which were completed by the parents for the younger age group and by the participants in the adolescent age group. Although it is likely that the parent who completed the questionnaire would be more accurate about their own tobacco use than that smoked by the other parent, we did not record which parent completed the questionnaire. This might lead to misclassification, which would reduce the chance of identifying associations, but is unlikely to result in any systematic bias. Selection bias is also unlikely as the response rate from centres included in these analyses was high.

The major limitation was absence of data on smoking by the participants themselves. Smoking by 6-7 year olds is unlikely, but is more likely in the adolescents. Adolescents who smoke are at greater risk of wheezing than those who had never smoked. ${ }^{20}$ However, there was consistency of findings across the two age groups, which suggests this potential bias is not important.

\section{Implications}

The association of ETS with asthma fulfils the criteria for a causal relationship. ${ }^{21}$ The association is moderately strong; the results were generally consistent across each of the centres; and a dose-response relationship was seen for asthma, but not eczema and rhinoconjunctivitis.

\section{Conclusion}

In summary, this study has confirmed the importance of maternal smoking, especially early in the child's life, and the separate and additional effect of paternal smoking. The presence of a dose-response effect relationship with symptoms of asthma suggests that the relationship may be causal. However, for eczema and rhinoconjunctivitis causality is less certain.

Acknowledgements We are grateful to the children and parents who participated in ISAAC Phase Three and the coordination and assistance by the school staff is sincerely appreciated. The authors also acknowledge and thank the many funding bodies throughout the world that supported the individual ISAAC centres and collaborators and their meetings. 
Contributors EAM is a member of the ISAAC International Data Centre, ISAAC Steering Committee member, led the analysis and wrote the first draft. RB is a member of the ISAAC Steering Committee, regional coordinator for North America, and advised on the manuscript. UK is a member of the ISAAC Steering Committee, regional coordinator for Western Europe, and advised on the manuscript. SM is a member of the ISAAC Steering Committee, regional coordinator for Eastern Mediterranean, and advised on the manuscript. JO is a member of the ISAAC Steering Committee, regional coordinator for Africa, and advised on the manuscript. All authors approved the final submitted manuscript.

Funding Currently the main source of funding for the ISAAC International Data Centre (IIDC) is The New Zealand Lotteries Grant Board. Many New Zealand funding bodies have contributed support for the IIDC during the periods of fieldwork and data compilation (the Health Research Council of New Zealand, the Asthma and Respiratory Foundation of New Zealand, the Child Health Research Foundation, the Hawke's Bay Medical Research Foundation, the Waikato Medical Research Foundation, The Auckland Medical Research Foundation, Glaxo Wellcome New Zealand and Astra Zeneca New Zealand). Glaxo Wellcome International Medical Affairs and The BUPA Foundation supported the regional coordination for Phase Three and the IIDC. Without help from all of the above, ISAAC would not have been such a global success. EA Mitchell is supported by Cure Kids (NZ).

Competing interests None.

Ethics approval Each participating centres obtained approval according to their laws and regulations.

Provenance and peer review Not commissioned; externally peer reviewed.

Data sharing statement At this moment in time the data are confidential to each centre and the ISAAC International Data Centre.

\section{REFERENCES}

1. US Department of Health and Human Services. The Health Consequences of Involuntary Exposure to Tobacco Smoke: a Report of the Surgeon General. Atlanta, GA: US Department of Health and Human Services, Centers for Disease Control and Prevention, Coordinating Center for Health Promotion, National Center for Chronic Disease Prevention and Health Promotion, Office on Smoking and Health, 2006.

2. Burke H, Leonardi-Bee J, Hashim A, et al. Prenatal and passive smoke exposure and incidence of asthma and wheeze: systematic review and meta-analysis. Pediatrics 2012;129:735-44

3. Ellwood P, Asher MI, Beasley R, et al; ISAAC Steering Committee. The International Study of Asthma and Allergies in Childhood (ISAAC): Phase Three rationale and methods. Int J Tuberc Lung Dis 2005:9:10-16.

4. Beasley R, Keil U, von Mutius E, et al. Worldwide variation in prevalence of symptoms of asthma, allergic rhinoconjunctivitis, and atopic eczema: ISAAC. The International Study of Asthma and Allergies in Childhood (ISAAC) Steering Committee. Lancet 1998;351:1225-32.

5. Crane J, Mallol J, Beasley R, et al; International Study of Asthma and Allergies in Childhood Phase I Study Group. Agreement between written and video questions for comparing asthma symptoms in ISAAC. Eur Respir J 2003;21:455-61.

6. Aït-Khaled N, Pearce N, Anderson HR, et al; ISAAC Phase Three Study Group. Global map of the prevalence of symptoms of rhinoconjunctivitis in children: The International Study of Asthma and Allergies in Childhood (ISAAC) Phase Three. Allergy 2009;64:123-48.

7. Lai CKW, Beasley R, Crane J, et al; The ISAAC Phase Three Study Group. Global variation in the prevalence and severity of asthma symptoms: Phase Three of the International Study of Asthma and Allergies in Childhood (ISAAC). Thorax 2009;64:476-83

8. Odhiambo J, Williams H, Clayton T, et al; ISAAC Phase Three Study Group. Global variations in prevalence of eczema symptoms in children from ISAAC Phase Three. J Allergy Clin Immunol 2009;124:1251-8

9. Beasley R, Clayton T, Crane J, et al; ISAAC Phase Three Study Group. Association between paracetamol use in infancy and childhood, and risk of asthma, rhinoconjunctivitis, and eczema in children aged 6-7 years: analysis from Phase Three of the ISAAC programme. Lancet 2008; 372:1039-48.

10. Hosmer DW, Lemeshow S. Confidence interval estimation of interaction Epidemiology 1992;3:452-6.

11. Benichou J. A review of adjusted estimators of attributable risk. Stat Methods Med Res 2001;10:195-216.

12. Rönmark EP, Ekerljung L, Lötvall J, et al. Eczema among adults: prevalence, risk factors and relation to airway diseases - results from a large scale population survey in Sweden. Br J Dermatol. Published Online First: 28 February 2012. doi:10.1111/ j.1365-2133.2012.10904.x

13. Bø K, Thoresen M, Dalgard F. Smokers report more psoriasis, but not atopic dermatitis or hand eczema: results from a Norwegian population survey among adults. Dermatology 2008;216:40-5.

14. Tanaka K, Miyake Y, Sasaki S, et al; Osaka Maternal and Child Health Study Group. Maternal smoking and environmental tobacco smoke exposure and the risk of allergic diseases in Japanese infants: the Osaka Maternal and Child Health Study. J Asthma 2008:45:833-8
15. Sebok B, Schneider I, Harangi F; Primary Care Paediatricians in Baranya County. Familiar and environmental factors influencing atopic dermatitis in the childhood. J Eur Acad Dermatol Venereol 2006;20:418-22.

16. Kramer $\mathbf{U}$, Lemmen $\mathrm{CH}$, Behrendt $\mathrm{H}$, et al. The effect of environmental tobacco smoke on eczema and allergic sensitization in children. $\mathrm{Br} J$ Dermatol 2004:150:111-18.

17. Hjern A, Hedberg A, Haglund B, et al. Does tobacco smoke prevent atopic disorders? A study of two generations of Swedish residents. Clin Exp Allergy 2001;31:908-14.

18. Magnusson LL, Olesen AB, Wennborg $\mathrm{H}$, et al. Wheezing, asthma, hayfever, and atopic eczema in childhood following exposure to tobacco smoke in fetal life. Clin Exp Allergy 2005;35:1550-6.

19. Civelek E, Yavuz ST, Boz AB, et al. Epidemiology and burden of rhinitis and rhinoconjunctivitis in 9- to 11-year-old children. Am J Rhinol Allergy 2010;24:364-70

20. Burr ML, Anderson HR, Austin JB, et al. Respiratory symptoms and the home environment in children: a national survey. Thorax 1999;54:27-32.

21. Hill AB. The environment and disease: association or causation? Proc $R$ Soc Med 1965;58:295-300.

\section{APPENDIX 1 \\ ISAAC Phase Three Study Group \\ ISAAC Steering Committee}

N Aït-Khaled* (International Union Against Tuberculosis and Lung Diseases, Paris, France); HR Anderson (Division of Community Health Sciences, St Georges, University of London, London, UK); MI Asher (Department of Paediatrics: Child and Youth Health, Faculty of Medical and Health Sciences, The University of Auckland, New Zealand) R Beasley* (Medical Research Institute of New Zealand, Wellington, New Zealand) B Björkstén* (Institute of Environmental Medicine, Karolinska Institutet, Stockholm, Sweden); B Brunekreef (Institute of Risk Assessment Science, Universiteit Utrecht, The Netherlands); J Crane (Wellington Asthma Research Group, Wellington School of Medicine, New Zealand); P Ellwood (Department of Paediatrics: Child and Youth Health, Faculty of Medical and Health Sciences, The University of Auckland, New Zealand); C Flohr (Department of Paediatric Allergy and Dermatology, St Johns Institute of Dermatology, St Thomas' Hospital, London, UK); S Foliaki* (Centre for Public Health Research, Massey University, Wellington, New Zealand); F Forastiere (Department of Epidemiology, Local Health authority Rome, Italy); L García-Marcos (Respiratory Medicine and Allergy Units, 'Virgen de la Arrixaca' University Children's Hospital, University of Murcia, Spain); U Keil* (Institut für Epidemiologie und Sozialmedizin, Universität Münster, Germany); CKW Lai* (Department of Medicine and Therapeutics, The Chinese University of Hong Kong, SAR China); J Mallol* (Department of Paediatric Respiratory Medicine, University of Santiago de Chile, Chile); EA Mitchell (Department of Paediatrics: Child and Youth Health, Faculty of Medical and Health Sciences, The University of Auckland, New Zealand); S Montefort* (Department of Medicine, University of Malta, Malta); J Odhiambo* (Centre Respiratory Diseases Research Unit, Kenya Medical Research Institute, Nairobi, Kenya); N Pearce (Department of Medica Statistics, Faculty Epidemiology and Public Health, London School of Hygiene and Tropical Medicine, London, UK); CF Robertson (Murdoch Children's Research Institute, Melbourne, Australia); AW Stewart (School of Population Health, Faculty of Medical and Health Sciences, The University of Auckland, New Zealand); D Strachan (Division of Community Health Sciences, St Georges, University of London, London, UK); E von Mutius (Dr von Haunerschen Kinderklinik de Universität München, Germany); SK Weiland $^{\dagger}$ (Institute of Epidemiology, University of Ulm, Germany); G Weinmay (Institute of Epidemiology, University of Ulm, Germany); H Williams (Centre for Evidence Based Dermatology, Queen's Medical Centre, University Hospital, Nottingham, UK); $G$ Wong (Department of Paediatrics, Prince of Wales Hospital, Hong Kong, SAR China).

${ }^{*}$ Regional Coordinators; ${ }^{\dagger}$ Deceased.

\section{ISAAC International Data Centre}

MI Asher, TO Clayton, E Ellwood, P Ellwood, EA Mitchell, Department of Paediatrics: Child and Youth Health, and AW Stewart, School of Population Health, Faculty of Medical and Health Sciences, University of Auckland, New Zealand.

\section{ISAAC Principal Investigators}

Argentina: CE Baena-Cagnani* (Córdoba), M Gómez (Salta); Barbados: ME Howitt*; Bolivia: R Pinto-Vargas* (Santa Cruz); Brazil: AJLA Cunha (Nova Iguaçu), L de Freitas Souza (Feira de Santana, Salvador, Vitória da Conquista); Cameroon: C Kuaban* (Yaounde); Canada: A Ferguson (Vancouver), D Rennie (Saskatoon); Channel Islands: P Standring (Guernsey); Chile: P Aguilar (South Santiago), LAV Benavides (Calama), A Contreras (Chiloe); China: Y-Z Chen* (Beijing, Tong Zhou), 0 Kunii (Tibet), 0 Li Pan (Wulumuqi), N-S Zhong (Guangzhou); Colombia: G Aristizábal (Bogotá), AM Cepeda (Barranquilla), GA Ordoñez (Cali); Cote d'Ivoire: BN Koffi* (Urban Cote d'Ivoire) Ecuador: C Bustos (Guayaquill); Estonia: M-A Riikjärv* (Tallinn); Ethiopia: K Melaku (Addis Ababa); Fiji: R Sa'aga-Banuve (Suva); Finland: J Pekkanen* (Kuopio County); Former Yugoslav Republic of Macedonia (FYROM): E Vlaski* (Skopje); Gabon: IE Hypolite* (Port-Gentil); Hong Kong: YL Lau (Hong Kong, 6-7 years), G Wong (Hong 
Kong, 13-14 years): Hungary: Z Novák (Szeged), G Zsigmond* (Svábhegy); India: S Awasthi (Lucknow), S Bhave (Rasta Peth), NM Hanumante (Pune), KC Jain (Jodhpur), MK Joshi (Mumbai (16)), VA Khatav (Borivali), SN Mantri (Mumbai (29)). AV Pherwani (Mumbai (18)), S Rego (Bangalore), M Sabir (Bikaner), S Salvi (Nagpur, Pimpri), G Setty (Chennai (3)), SK Sharma (New Delhi (7)), V Singh (Jaipur), TU Sukumaran (Kottayam), PS Suresh Babu (Davangere); Indonesia: CB Kartasasmita (Bandung), P Konthen (Bali), W Suprihati (Semarang); Iran: M-R Masjedi* (Rasht, Tehran); Isle of Man: A Steriu (Isle of Man); Japan: H Odajima (Fukuoka); Kuwait: JA al-Momen (Kuwait); Kyrgyzstan: C Imanalieva* (Balykchi, Bishkek); Lithuania: J

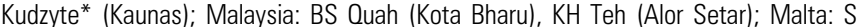
Montefort* (Malta); Mexico: M Baeza-Bacab* (Mérida), M Barragán-Meijueiro (Ciudad de México (3)). BE Del-Río-Navarro (Ciudad de México (1)). R García-Almaráz (Ciudad Victoria), SN González-Díaz (Monterrey), FJ Linares-Zapién (Toluca), JV Merida-Palacio (Mexicali Valley), N Ramírez-Chanona (Ciudad de México (4)). S Romero-Tapia (Villahermosa), I Romieu (Cuernavaca); Morocco: Z Bouayad* (Boulmene, Casablanca, Marrakech); New Zealand: Ml Asher* (Auckland), R MacKay (Nelson), C Moyes (Bay of Plenty), P Pattemore (Christchurch), N Pearce (Wellington); Nigeria: BO Onadeko (Ibadan); Panama: G Cukier* (David-Panamá); Peru: P Chiarella* (Lima): Philippines: F Cua-Lim* (Metro Manila); Poland: A Brêborowicz (Poznan), G Lis* (Kraków); Portugal: R Câmara (Funchal), JM Lopes dos Santos (Porto), C Nunes
(Portimao), JE Rosado Pinto* (Lisbon): Samoa: P Fuimaono (Apia): Singapore: DYT Goh (Singapore); South Africa: HJ Zar* (Cape Town); South Korea: H-B Lee* (Provincial Korea, Seoul); Spain: A Blanco-Quirós (Valladolid), RM Busquets (Barcelona), I Carvajal-Urueña (Asturias), G García-Hernández (Madrid), L García-Marcos* (Cartagena), C González Díaz (Bilbao), A López-Silvarrey Varela (A Coruña), MM Morales-Suárez-Varela (Valencia), EG Pérez-Yarza (San Sebastián); Sudan: OAA Musa (Khartoum): Sultanate of Oman: 0 Al-Rawas* (Al-Khod): Syrian Arab Republic: S Mohammad* (Tartous), Y Mohammad (Lattakia), K Tabbah (Aleppo); Taiwan: J-L Huang* (Taipei), C-C Kao (Taoyuan); Thailand: M Trakultivakorn (Chiang Mai), P Vichyanond* (Bangkok): Tokelau: T losefa* (Tokelau): USA: HH Windom (Sarasota, Florida); UK: M Burr (Wales), D Strachan (Surrey/Sussex); Uruguay: D Holgado* (Montevideo), MC Lapides (Paysandú): Venezuela: 0 Aldrey* (Caracas).

*National Coordinator.

ISAAC Phase Three National Coordinators not identified above

Canada: M Sears; Channel Islands: HR Anderson; Chile: V Aguirre; Hong Kong: CKW Lai; India: J Shah; Indonesia: K Baratawidjaja; Isle of Man: HR Anderson; Samoa: N Tuuau-Potai; Singapore: B-W Lee; Sudan: A El Sony. 